\title{
Old sounds with new technologies? Examining the creative potential of gui- tar 'profiling' technology and the future of metal music from producers' perspectives
}

Innovations in music technology have the potential to change practices of music making and to contribute to the development of new forms of music. In 2011, a 'profiling' technology was released, capable of copying any valve guitar amplifier and shaping every detail of its sound. Many rock and metal guitarists and producers embraced this new technology, and the renowned producer Michael Wagener even claimed it to be "the biggest innovation for recording at least for the last fifteen years". Building on an initial study on the quality and public reception of profiling technology in a metal music context, this article explores the attitudes of metal music producers towards new guitar amplification technologies, their uses thereof, and their conceptions of future music including the role of technological inventions. The findings indicate that although most producers experiment with modern technologies, they regard these as special effects or backup solutions. Traditional guitar sounds and engineering practices are still preferred, partly as a strategy to retain distinction between their established businesses and new enterprises. Developments in music technology are viewed sceptically regarding its positive contribution to future music.

\section{Introduction}

Every once in a while, innovations in music technology alter established practices of music making, allow new means of expression, and even contribute to the development of new subgenres of music. In metal music, the electric guitar has had a crucial role from the beginning (Walser 1993: 42; Berger 1999: 58f), and clearly, metal guitar sounds have changed in the genre's history. Technological advancements as for instance in the amplifiers' increased capabilities to produce distortion and lower frequencies, additional resonance and presence controls, but also seven or eight string guitars resulting in lower tunings plus changing trends in production regarding the layering of guitar tracks have contributed to the different sounds of metal's subgenres (Herbst 2017). Despite this shift in aesthetics, the electric guitar is an instrument whose players are tending to disapprove of technological innovation, still favouring vintage guitars and valve amplifiers already available in the mid-20 $0^{\text {th }}$ century. Digitalisation has gradually found its way into guitar technology since the 1990s, and the improved quality of modern modelling amplifiers and plugin simulations have increasingly convinced guitarists and music producers (Eichenberger 2015). Yet, many guitar players prefer old valve designs as a recent quantitative study of 413 electric guitarists indicates (Herbst 2016).

In 2011, the German company Kemper Ltd. released a guitar amplifier based on a new profiling technology. Intrigued by the complexity of valve guitar amplifiers and the limitations of modelling technology, Christoph Kemper invented a profiling device capable of copying the sound and playing feel of any valve amplifier at hand. Technically, a signal is sent from the profiler to the amplifier to be profiled. The amplifier's sound is recorded with a microphone and the signal is sent back to the profiler to be analysed. By sending test tones such as sinewaves, white noise and needle pulses, and optional guitar signals for a refinement, the profiler analyses the amplifier's nonlinearities and recreates a virtual copy of the signal flow, including even the characteristics of the speaker cabinet, the microphone with its placement and optional effects pedals (Kemper 2016: 8). The prospect of profiling and modifying personal guitar sounds has proven to be highly attractive, especially for music production purposes. Options of shaping the sound comprise the change of gain structure whilst retaining the characteristic 
amplifier features, the effective equalisation at the sound source and the modification of transient characteristics by altering the picking sound as well as setting the overall resolution important for the perceptibility of individual notes in a chord. Furthermore, a layering function allows the merging of sounds, produced by different amplifier sounds, cabinets, speakers and microphone positions, into a new sound not possible with just one guitar and amplifier. Leading rock and metal producers thus have praised the profiling technology. Andy Sneap (2012: 5:40) predicted profiling technology to "move recording forward the same way as Pro Tools has" and Wagener (2013: 6:40f) concluded that it was "the biggest innovation for recording at least for the last fifteen years".

Surprisingly, the huge impact of profiling technology on musical practice has not stirred an academic debate so far. Only one study by Herbst, Czedik-Eysenberg and Reuter (2018) has recently explored this technology in a metal music studies context. With an experimental design, the study confirmed the high quality of profiled guitar sounds. Moreover, qualitative analyses of online discussion boards and magazine reviews indicated that music producers, in contrast to guitar players, might not merely see the benefit of profiling in the capability of copying sounds. Prospects rather arise from transforming a vintage amplifier into a high-gain device, shaping the signal's envelope without any natural counterpart, combining and layering sounds of various preamplifiers, power amplifiers, cabinets and miking choices plus a large selection of digital effects. All this has the potential of creating sounds unheard of before. In the everlasting quest for greater heaviness (Berger \& Fales 2005; Mynett 2013, 2017; Herbst 2017, 2018) or for developing new subgenres of metal, such sounds could be beneficial.

This article builds on the initial study by interviewing four internationally active professional German metal music producers. Producers rather than musicians were approached both to add to the guitar players' views described in the initial study and to locate the context of the research to the music studio. This research shares Bates' (2012) understanding of recording studios as "meeting places, as container technologies, as a system of constraints on vision, sound and mobility, and as typologies that facilitate particular interactions between humans and nonhuman objects while structuring and maintaining power relations". The studio is a place of intense interaction between the producer, the musicians, recording and performing technologies, where current attitudes and practices come to light and might be challenged. Following Auvinen's (2016: 10) techno-cultural perspective of music production, technologies are understood as "systems complexly bound up with surrounding cultural practices and as systems that are shaping cultural meanings of music". The recording studio thus is an important place where cultural changes of future music are likely to happen, even before they are made available to the audience on a live stage or as a released audio product."

In this research project, profiling technology served as a starting point for investigating musical change through technological development. The interviews aimed at exploring the producers' personal views and practices, regarding both current engineering approaches of the guitar and more general deliberations on the future of metal music including the role of music technology. In addition to the producers, the inventor of profiling technology and CEO of Kemper Ltd., Christoph Kemper, was interviewed.ii He also gave insights into the use of this technology and presented his views as an inventor about future technological and musical developments. Against this backdrop, the present study was guided by the following research questions: What are metal music producers' attitudes towards new guitar amplification technologies? How do they use profiling and related digital technology? How do producers and music instruments developers imagine the role of music technological inventions for future metal music? Based on the initial study (Herbst, Czedik-Eysenberg \& Reuter 2018), research on guitar players (Herbst 2016) and metal music production (Mynett 2013; Williams 2015; Herbst 2017), it was assumed that producers are more interested in finding new approaches to 
create innovative guitar sounds than guitar players are. Accordingly, a positive view of technological innovation was expected.

\section{Method and sample}

Fifteen professional music producers from Germany renowned for their work in diverse subgenres of rock and metal music were invited to take part in the study. Out of these requests, four were positive, who all were metal music producers. Some rock producers also responded but since they did not know or use profiling technology, they did not regard themselves as suitable interviewees for this research project. This outcome concurs with previous research findings of metal musicians being more open towards newer music technologies (Herbst 2016: 273-347). Consequently, the interviews aimed at metal rather than rock productions.

The producer interviews took place between 19 June and 27 July 2017. All interviewees consented to their name being used in the research project. The overview of the producers' sociodemographic data (Table 1) shows that the sample consisted of successful producers with different levels of experience and formal specialist education. Unfortunately, the sample does not include female producers as the search for internationally active rock and metal producers did not show any respective results in Germany.

Table 1: Sociodemographic data of the music producers

\begin{tabular}{|c|c|c|c|c|}
\hline & $\begin{array}{l}\text { Sebastian 'Seeb' } \\
\text { Levermann }\end{array}$ & Lasse Lammert & $\begin{array}{l}\text { Karl Rudolf 'Char- } \\
\text { lie' Bauerfeind }\end{array}$ & $\begin{array}{l}\text { Siegfried 'Siggi' } \\
\text { Bemm }\end{array}$ \\
\hline Main studio & $\begin{array}{l}\text { Greenman Studios, } \\
\text { Arnsberg }\end{array}$ & $\begin{array}{l}\text { LSD Studio, } \\
\text { Lübeck }\end{array}$ & $\begin{array}{l}\text { Twilight Hall Stu- } \\
\text { dios, Grefrath }\end{array}$ & $\begin{array}{l}\text { Woodhouse Studio, } \\
\text { Hagen }\end{array}$ \\
\hline Renowned clients & $\begin{array}{l}\text { Orden Ogan, Al- } \\
\text { manac, Rhapsody } \\
\text { of Fire, Thorn- } \\
\text { bridge, Asenblut, } \\
\text { Heaven Shall Burn }\end{array}$ & $\begin{array}{l}\text { Alestorm, Glory- } \\
\text { hammer, Svartsot, } \\
\text { Inner Sanctum, } \\
\text { Killfloor Me- } \\
\text { chanic, Twisted } \\
\text { Wrath }\end{array}$ & $\begin{array}{l}\text { Blind Guardian, } \\
\text { Saxon, Rob } \\
\text { Halford, Gamma } \\
\text { Ray, Angra, Hel- } \\
\text { loween, Molly } \\
\text { Hatchet, Rage }\end{array}$ & $\begin{array}{l}\text { Angel Dust, } \\
\text { Tiamat, Phantoms } \\
\text { of Future, The } \\
\text { Gathering, Therion, } \\
\text { Caliban }\end{array}$ \\
\hline Education & $\begin{array}{l}\text { Popular Music and } \\
\text { Media, University } \\
\text { of Paderborn, Ger- } \\
\text { many }\end{array}$ & $\begin{array}{l}\text { Music, Production } \\
\text { \& Engineering, } \\
\text { McNally Smith } \\
\text { College of Music, } \\
\text { USA }\end{array}$ & $\begin{array}{l}\text { Music, Production } \\
\text { \& Engineering, } \\
\text { Berklee College of } \\
\text { Music, USA }\end{array}$ & Autodidact \\
\hline Instruments played & Guitar, bass, vocals & Guitar, bass, drums & Piano, drums & $\begin{array}{l}\text { Guitar, bass, } \\
\text { drums, keyboards, } \\
\text { vocals }\end{array}$ \\
\hline Experience & 7 years & 10 years & 30 years & 45 years \\
\hline Age & 35 years & 36 years & 54 years & 61 years \\
\hline Sex & Male & Male & Male & Male \\
\hline
\end{tabular}

'Charlie' Bauerfeind and 'Siggi' Bemm were interviewed in their studios, Lasse Lammert via Skype and 'Seeb' Levermann by phone. Levermann preferred the interview not to be recorded. He felt not having enough to offer because after a short phase of experimentation, he rarely uses profilers in his studio but rather on stage. Therefore, only written notes were available in his case.

The research followed a semi-structured interview design with a schedule. The first block aimed at the producer's attitudes towards digital guitar technology, the influence of profiling technology on their working practices, intended sound aesthetics and the use of sound design functions. The second block addressed the future development of music and music technology. Christoph Kemper was interviewed after the producers. He commented on selected producer statements, gave insights into the company's plans on the profiling technology, and reflected 
on the future of music and technology as well. All interviews took between 32 and 136 minutes. They were transcribed focussing on content, meaning that prosodic aspects such as pause lengths and nonverbal utterances did not have to be transcribed. The analysis and interpretation process was inductive. Significant statements were highlighted, themes noted, similar themes clustered hierarchically and summarised following general guidelines of qualitative research (Cresswell 2003; Denscombe 2007). Since the interviews were conducted in German, the direct quotes were translated into English as authentically as possible. Linguistic shortcomings were only corrected if otherwise the quotes would not have been understandable.

\section{Results}

\section{Attitude towards new guitar amplification technologies}

Asking producers about their views on profiling technology indirectly provided insights into their attitudes towards newer music technologies. The answers were not always clear and indicated ambiguous if not conflicting views. In general, all producers show an interest in technological developments demonstrated by experimentation. Yet, this does not mean that they are easily convinced of the benefits of newer technology. Bauerfeind, one of the interviewees most open to technological innovation, explains having been an enthusiastic user of digital convolution technology as a means of creating character in his productions for a long time. He experimented with impulse responses to capture guitar cabinets and microphone setups before profiling technology emerged. Similarly, Bemm tried out the Roland guitar synthesisers and was surprised by the authenticity of the sounds. Yet, he always comes back to his proven tools as for him the audio quality and controllability of analogue equipment is superior to digital technology. He however stresses to be willing to use the tool that the purpose requires, irrespective of being analogue or digital. Although the quality of digital technology has increased in the last 30 years, for him the lacking quality compared to analogue equipment makes digital tools mainly usable as special effects but not as means to create the fundamental sounds of a production. Especially artefacts in the harmonic spectrum are a major downside for him.. Digital technology excelled at 'hacking' sounds, and this is how he uses it. He produces the main recordings with valve amplifiers, and if he does not have the right models, he would loan them from his professional network. Lammert, one of the younger producers, shows a lot more ambiguity. When being asked about his initial opinion of profiling technology he said, "I have been very sceptical for a long time. To be honest, I did not want it to sound good". He admits not to have a rational explanation. Instead, he rather expresses a fundamental disapproval, "It just is my inner refusal". Even though he eventually integrated profiling technology into his work routine, he gives the impression to be pressured by industry standards, as it is the case with other studio tools like Auto-Tune. However, Lammert was convinced of the profiler's quality in the end, but still he restricts its use to recreate rare clean or solo sounds, similar to Bemm's use of digital technology for special effects. What is more, Lammert does not improve an authentic profile even if it was possible, "Principally, I don't change or improve an authentic profile. Actually, it is a good thing that you are able to change the profile but my head does not like that. To change a profile later so that it sounds different to the original amplifier, I don't like that". Thus, he would change the sound at the mixing stage rather than in the profiler. If the sound needed more than just some minimal EQ corrections, he would prefer to profile the sound again with a different miking, claiming his approach being "old school". Still, he acknowledges the important role of profiling as a producing professional and hence he has released official "rig packs" that are sold by Kemper Ltd. He also profiles guitar sounds in his productions and offers profiling to every client. However, he is very clear about his preference for 'real' amplifiers, stating, "It is sexier to work with amps than with a digital box". Especially the occasional opportunity to record rare amplifiers is exciting to him. In contrast to Lammert, 
Levermann was interested in this new technology from the start but sees its benefits mainly for the touring musician; both guitarists of his band Orden Ogan play a profiler amplifier live. In a studio context, he also prefers the slightly better quality of the traditional valve amplification, using the profiler primarily for backup purposes. Ultimately, all interviewed producers do favour their traditional routines and the sounds they create.

Apart from the perceived lack of quality, there were other reasons for mistrusting digital guitar amplification technology. All producers highlighted their intent to make decisions early in the production process. Consequently, they want to have the target sound at the recording stage. Bauerfeind describes that in many of his productions the sounds are determined by agreeing on the guitars, amplifiers, miking and processing before the recording takes place. He stresses the endless opportunities of digital amplifiers as their biggest pitfall since these complicate to take a decision. Furthermore, in a commercial context where time is limited, comparing distorted sounds posed a risk of ear fatigue, possibly ending the recording session for the day without the scheduled result. Similarly, Lammert admits that the option to change sound settings in the mixing stage are tempting, but in his experience hardly ever leading to better results. This corresponds to Bauerfeind's and Bemm's experience of changing sounds in the mixing stage risk destroying the definition and intelligibility of the instruments in their musical context. Furthermore, all producers feel that digitally produced sounds are less transparent in the mix. Finally, they all stress their rejection of presets of any kind, and this translates to digital technology. Even though they create their own profiles, they are keen to avoid using the same sounds on different productions. Lammert however reflects that every producer has a style and a personal taste, "In the end, I will always place the microphone as usual, select the amplifier that I like most, and then I will end up with a similar sound". The risk of sounding like someone else is the reason for Bauerfeind's disinterest in vintage guitar sounds. He would rather use the "character sound" of an old amplifier and mix it with another device to create something more original.

\section{Profiling in the guitar recording}

All producers but Bemm create profiles of the guitar sounds created by valve amplifiers when working on a production. Lammert explains, "Sometimes you notice that something has to be changed and when you have moved the microphone, you will never find the same sound again. Then, the Kemper is very useful". He continues to describe a production in which the recorded guitar tracks had to be pitched down two semi-tones because the singer could not perform in the recorded key. By using the profiler's pitch-shift function, this problem had been solved easily whilst retaining a good sound quality.

In line with Bemm's view of digital technology serving as an effect, all producers highlighted profiling to be useful for special sounds. Under normal circumstances, Lammert would not record the main rhythm tracks with the profiler. Instead, he may use profiles he created in earlier sessions for particular clean or solo sounds. Correspondingly, Bauerfeind recollects several recording sessions where old and rare amplifiers had to be repaired after one song due to the extreme load common in a metal music production. These rare sounds cannot be recreated with other amplifiers, which is why he uses profiles to preserve the original devices.

When it comes to creating new or unconventional sounds, the producers differ in their views about profiling technology. For Bemm, the artists' intentions are most important, and he supports them even if their choice of equipment contradicted his personal preference. Lammert acknowledges the possibilities to shape the sound in a profiler beyond what is possible with the original amplifier and a mixing device. However, he would not use these options if he could prevent it by other means. Bauerfeind, in contrast, uses profiling to create original sounds. He expounds: 
"I always profile a guitar sound for my productions. With it, I don't only have profiled the basic sound, the basic character, of the amplifier but to a certain extent also the EQ settings, the responses of the valves etc. That means I have created a new basic sound that I can change with all the options that the Kemper provides: increase distortion or whatever. This is a big advantage because I can take a very characteristic Marshall sound, and it will only distort to a certain degree. Then I start modifying this basic sound to get the sound I want."

This approach was also useful for modifying the compression behaviour of the valves. In most cases, Bauerfeind does not intend to recreate vintage sounds, but he tries to combine "tonal attributes" of different amplifiers and to blend various sounds from old to modern. For this approach however, a profiler by itself was not sufficient, it required mixing in a desk or digital audio workstation. Therefore, he wishes for a profiler release that included more than one profiling module. ${ }^{i}$ In addition to this creating of general sounds, Bauerfeind highlights the usefulness of the profiler's controls to support the guitar player. For example, he regularly uses the transient function to restore some of the attack and plectrum noise of a guitar played with active pickups. In other cases, he would reduce the attack in fast passages to achieve a smoother sound. Ultimately, he agrees with Bemm that supporting the artists and their creative intentions was far more important than producing unconventional guitar sounds.

At the end of the day, the sound processing options of the profiler are rarely used, which Kemper confirms, "I do know how much this is used, practically not at all. This really does not interest anybody, to create new sounds or so. Or new forms of expression". All producers agree that current guitar sounds are perfect and thus they see no need to develop them in any new direction. Kemper further states that he does not intend to explore new guitar sounds with his company. For him the reason profiling is interesting for the guitar is the variety of sounds possible with traditional means:

"And why are there unlimited guitar sounds? Because the options of miking a speaker are so diverse. The amplifier itself is much less dimensional. It does not have so many settings, but combine the amplifier with a different set of speakers, the position of the microphone, the combination of microphones and their resulting phases etc. That is what makes profiling so valuable. And I believe this is not as attractive with a different instrument, effect or signal chain."

Kemper also explains that profiling technology was almost perfect and therefore his company has been focusing on integrating high-quality effects into the profiler in the last years. This is what the customers were interested in; not exploring new sound worlds but having great sounds in one device as conveniently as possible.

The statements of Kemper and the producers all indicate that it is possible to create such a plethora of guitar sounds that no further development is required. Still, this does not mean that metal producers do not value the quality of their guitar sounds. Lammert elucidates:

"The guitar sound in 'heavy music' is such an important aspect of the whole mix. [...] It is such a strong finger print. [...] This is why I am really careful when it comes to my personal profiles and I don't want to give them away. I always tell my bands never to share them with anyone."

Similarly, Bauerfeind does not send in his profiler for a service update as not to let the guitar sounds of commercial albums out of his hands.

\section{The influence of technology on the development of metal music}

The second part of the interview schedule was more general, intending to capture the interviewees' opinions about the relation between technological innovation and musical development. Although metal producers could be expected to be open-minded about the chances of modern technology in the quest to produce innovative and increasingly processed sounds ${ }^{\text {vii }}$, exactly the opposite is the case. Taking again the example of a profiler, Lammert criticises that 
the modern guitarist lacks the need to find an individual playing style due to the ubiquity of available sounds, notably a result of modelling and profiling amplifiers. Playing had to be adjusted to the musical equipment because of the way it responds to it, and having a limited selection of equipment would shape the sound and the playing of the performer, as Lammert explains:

"This limitation is valuable. The old thrash metal guitar players, for example, had such a great sound
because they played the old Marshall 800 s that required the attack of the picking hand to be like a
sledgehammer. And they had to play like this because they did not have the gain of the [Peavey] 5150
that lets everybody sound the same. These amps, and the limitations, were crucial for the development
of that style. Therefore, it is contra-productive if every twelve-year old beginner has all the sounds in
the rehearsal room. I just think it isn't wrong to have to struggle because then you will develop a unique
style and sound."

The underlying critique of laziness becomes even better visible in Bemm's reflection of his over 40-year long experience as a music producer:

\begin{abstract}
"If I look back in time, then I have to be quite clear. The people I worked with in the "70s and ' 80 s were much more capable than the people are today. I notice a certain laziness. That is a danger. You have played a riff in the verse, if it is good, copy and paste it. 'Why should I play it again? That's nonsense. I could just copy it.' I notice the people stop working on their skills. Of course, there are exceptions. But laziness is becoming increasingly more common, especially among the young bands. $80 \%$ of the bands I am recording aren't able to record on analogue devices because the drummer cannot play a whole song. [...] It is strange, I listen to my recordings from the ' 80 s with people just as young, and you think, wow, totally brilliant. And they had to play it. I didn't replace the drum sounds. And today, there hardly is a band that can play like this. To be honest, I don't think that technology creates or supports virtuosity."
\end{abstract}

This laziness among artists and their understanding of technology as a tool to correct or improve lacking commitment and skills is a coherent issue mentioned by the producers. Bemm as the most conservative producer, still solely mixing on an analogue Raindirk Symphony console, highlights the danger of using technology without musical reason the most. For him, all technology is just a means to support the music, "The artist is what's important, not the computer. And that is the reason I still use this console. It does not have ones and zeros".

Bauerfeind is even more cynic about the development of future music. The problem he does not see in the technology itself but in the music industry. He stresses the increasing challenge to live from music, resulting in time for song writing being limited, "In past times, you have employed songwriters. They have written songs all day. Let's say, they have written two per day, ten per week. Out of the ten, nine were rubbish, but maybe one was great". Also in the changed practices of bands writing and recording songs not as a group but from home or individually in the studio he sees a risk for high quality music:

"A globalised performance. Why do I doubt that this will result in something great? All these companies propagate online collaboration. What is collaboration? For me, collaboration is when we shout at each other sometime. 'Say, what is this shitty riff? Play something good, play the other riff. What do you want with this old stuff? Let's try this. I'll punch you... Let's go home and try again tomorrow.' That is collaboration. This is how something great can come out."

In the end, technology is not crucial in Bauerfeind's view; it is the quality of the music itself that he feels is decreasing. What is more, he does not think the technical quality matters much to listeners who consume music on streaming services through cheap reproduction devices.

In line with the producers, musical instruments developer Kemper is sceptical about future technological innovation taking influence on the music as well. This already happened with the invention and broad availability of the personal computer and music software. Nowadays it was the musician who posed the limiting element as the technology was already capable of performing most if not everything that was required by the musicians and producers. He rather 
experienced that customer wishes and musical development "do not correlate at all". As he explains, the recent effects his company developed are played mainly by guitarists at home because they are too opulent in a band context, "Especially the effects that people were asking for will be heard on very, very few recordings. And these inventions do not contribute to the development of the music at all. Not at all". He continues to explain that inventors "can only make the musicians a technical offer [...] and hope that someone will use it creatively". However, he states not to have seen much development in rock and metal music since the 1980s. Few guitar players were experimental, especially in the harder genres. Progressive rock and metal were an exception, less in their use of technology but in creating modern sounds as for instance with seven and eight string guitars. Rather, he sees a revival of 1970s rock: "It is newly interpreted, shaped by other paradigms, catchier, they don't dread simple melodies. This is very interesting". .iii But despite the impact of profiling on many musicians worldwide, Kemper regards his invention modestly, "We didn't reinvent the music. We just have improved an existing technology, raised it to another level. But we didn't write music history, and this is not what we had in mind."

Even though all interviewees share a pessimistic view about the deteriorating quality of the music, they do not think that technology would shortly replace real musicians. Today, it still is impossible to programme and play back electric guitar performances authentically by technical devices in contrast to drums and many piano sounds. Kemper explains:

\begin{abstract}
"Drums and keyboards are rather easy to be virtualised because they are percussive instruments in the widest sense. They sound after being hit and are not modulated any further by the musician. Therefore, the sound is little dimensional. We have a countable input, the pitch in the case of a keyboard, the instrument in the case of a drum set. Also, we have the volume. In the case of a drum set, we have the position of the attack but this is also one-dimensional, more in the middle or to the edge. But the instrument sounds more or less the same within the same region, if you hit it left or right. [...] These rather simple dimensions do not exist in the case of the voice, the saxophone or the guitar."
\end{abstract}

The profiling technology may be capable of reproducing the timbral details of complex guitar sounds, but according to Kemper, it still is not sufficient to imitate a guitarist with all the subtleties of guitar playing. Furthermore, the company does not intend to create such a technology. Even though it may be possible, Kemper himself is not convinced that this is what musicians and listeners would want to have. Bemm shares this reflection. Although he is convinced that one day basic rhythm guitars can be programmed in a quality sufficient for a pop song, he agrees with Kemper that the personal sounds of attacking the strings, the way of palm muting and playing artificial harmonics plus the art of bending notes may be hard to simulate, especially when it comes to the melody guitar. With the guitar being such a prominent instrument in metal music requiring virtuoso skills, he does not believe its performance can be simulated by a computer soon. Moreover, the scenario of a computer replacing the musician is dreadful for him. This is one reason he uses the powerful tools of digital technology so rarely, "Small flaws are important, and a slight detune may lead to a feeling that is meaningful. If you start looking at everything only from a technical viewpoint, then you can just programme everything". This corresponds with Lammert's notion of his role as a producer. All technological development had shifted the producer's focus from artistic to technical tasks. He prefers artistic work and perceives technology ambiguously since it inevitably determined his practices but also served as a creative tool.

\title{
Discussion
}

This article was guided by two assumptions based on the initial study by Herbst, Czedik-Eysenberg and Reuter (2018) and previous research on guitar players (Herbst 2016) and metal 
music production (Mynett 2013; Williams 2015; Herbst 2017): 1. Metal producers are interested in creating innovative guitar sounds; 2 . Metal producers generally are positive towards technological development. Both assumptions were partly true. The producers were interested in creating original sounds within genre conventions but did not see much need for producing utterly new guitar sounds. They also experimented with modern technologies and incorporated them into their practice when evaluated positively, which however was not always the case. This general attitude distinguishes the producers of this survey from many of the amateur and semi-professional musicians and producers who were analysed in the initial study (Herbst, Czedik-Eysenberg \& Reuter 2018) based on online discussions and magazine reviews. For example, all 24 analysed reviews showed a principal distrust in digital technology, "Our culture is bound up in ritual, superstition and myth - and we like it that way. We know great tone and it sure as hell doesn't come from ones and zeroes" (Vinnicombe 2012: 119). Different to the metal producer's opinions, the reviewers' initial attitudes were not based on the actual quality of the technology. For example, Greeves (2012) highlighted the "impressive sense of depth, detail and realism to the amp sounds on offer, both in terms of tone and the way they respond to playing dynamics", and Davodowich (2015) praised the device being able to "capture those small nuances to such a degree that playing our profiles truly feels like we are playing through the actual amps. We didn't have to try and squeeze the feel and tone from our fingers - it was present and as accurate as the real amplifier". Although the profiler was mostly evaluated favourably in the end, reviewers and message board users were generally more sceptical than most of the interviewed metal producers who principally had a positive attitude towards modern technologies. Especially the more experienced producers, Bemm and Bauerfeind, demonstrated a history of experimenting with digital technology. Their criticism was much more founded in solid reasons such as their belief in the benefit of making decisions, of following a vision, mixing problems, and in the rejection of presets and already 'used' sounds. They give the impression to be open towards new technologies and that only its perceived inferior quality prevents them from using the new tools more often. However, this critique focused at the audio quality is weighted by pragmatic decisions. In the end, all producers but Bemm use profiling regularly for various reasons, be it an additional source of income (Lammert), a substitution for rare sounds or amplifiers (Lammert, Bauerfeind, Levermann), a safety net, or to create individual sounds (Bauerfeind).

Profilers with their capability to store many guitar sounds can be valuable in a studio, especially in rock and metal productions that require specialised and high-quality sounds (Wagener 2013: 7:00f). The producers make it very clear that they are not using stock profiles but always create new ones for every production. Only on rare occasions they would use a profile again, for instance when an uncommon or vintage amplifier was not at hand or at risk of failing. Thus, they value a large collection of amplifiers and loan rare devices from their professional network to create sounds that not everybody has access to. Such a high importance of gear collections contradicts findings of Martin's (2014: 262ff) study, showing that many professional British music producers prefer not to compete with others by means of technical equipment. Likely, the producers' main genre of work being metal music does provide an explanation. As they unmistakably make clear, unique guitar sounds are of utmost importance to metal productions and their clients, so creating new sounds for every project serves both an economic and an artistic purpose, and it is tied to their ethos as professional producers and artists in their own rights. What is more, large amplifier collections can be a distinctive difference between studios operated by successful producers and aspiring competitors. Since the availability of recording tools has shifted the "dominant networks of power" (Théberge 2004: 773), sticking to the old equipment seems to be a promising strategy of producers to counter the democratisation of production tools (Jones 1992; Théberge 1997; Leyshon 2009), espe- 
cially in times when analogue sounds are glorified (Kaiser 2017). For younger, already established producers, this can take the form of having a large collection of valuable guitar equipment - Lammert's guitar equipment for example includes about 30 guitars, 35 amplifiers, more than 30 effects pedals and ten cabinets that he proudly showcases on his studio website ${ }^{\mathrm{x}}$. For more experienced producers as in the case of Bemm, analogue consoles, tape machines and expensive microphones can be crucial capital distinguishing highly professional from amateur productions. .i $^{\mathrm{i}}$ In other words, as profiling technology means a huge benefit for aspiring musicians and producers alike regarding the availability of both a variety of sounds and sounds of professional quality (Herbst, Czedik-Eysenberg \& Reuter 2018), the established producers' preference of traditional working practices and tools could be interpreted as their attempt to retain distinction between their proven craft and the threats posed by newer technologies managed by rivalling producers and studios. Similarly, even though all producers demonstrate a high level of technical skills, creative intentions mainly motivate their work, which means that the artist is more important than their personal agendas. This self-perception of the producer's role corresponds to the classical view of the producer being the creative nurturer of his artists (Kealey 1982: 103f). Sticking to these traditional roles may be understood as another strategy by established producers against the powerful new technologies in the hands of younger competitors. This interpretation is supported by Lammert who regards the democratising of studio tools as beneficial at least in the prospect that the creative craft of the producer in its traditional role would be strengthened again. Economically, he sees a tense competitive situation in affordable production tools, but he hopes that at least the artistic abilities would be given more weight in distinguishing the outstanding producers from the mediocre ones.

The outlook of the initial study (Herbst, Czedik-Eysenberg \& Reuter 2018) highlighted the prospect of creating innovative sounds with profilers and the potential to create new subgenres of metal music, "With the guitar steering increasingly towards the digital domain due to this newly established high quality, guitar sounds may change more radically than they have in the last two decades - and along with this also the sound of the metal genre". All producers as well as inventor Kemper make it clear that drastic developments are neither expected nor desired in the near future. Most musicians and producers seem satisfied with the equipment available and the sounds it produces. Although they are principally open towards newer technologies, producers arguably more so than guitarists, the electric guitar seems like a finished instrument with little room for further improvement. Motivation for change predominantly is convenience, for instance reducing weight, storing everything in one box for reducing the need of long pedal boards, and, in a live context, eluding some of the technical problems such as interferences due to long cable ways, bad miking and insufficient monitoring. All these benefits hardly relate to work in the recording studio, so profiling, just like other digital guitar equipment, mainly serves as effect or backup solution. Ultimately, the greater openness of metal compared to the more tradition-conscious rock music (Herbst 2016: 297ff; Uimonen 2016; Herbst 2017) has its limits. Greater control over the sound is used for rhythmic precision rather than for more detailed sonic shaping or the creation of sounds unheard of before.

Apart from the guitar, the interviewed professionals do not consider modern technology as limiting factor of musical development; rather they criticise the decreased quality of artistic craftsmanship, regarding both playing skills and compositional vision. Instead of focussing on new technologies for the creation of future music, they prefer intelligent combination of traditional musical elements over too radical new paths. In the end, musical emotion and the artists' stories are what matter most. Producers will support the artists in this endeavour but they probably will not be the ones pushing for new sounds. Likewise, musical technology developers will balance their artistic intentions with economic decisions. Although there will be those working on technologies potentially replacing human musicians, few want human imperfection 
and creative craft to be replaced by computer music - at least not in rock and metal, music genres that value human musical craft (Moore 2002).

\section{Conclusion}

This study took guitar profiling technology as a starting point to explore the metal music producers' use of digital technology and to gain insights into future musical development, understanding the recording studio as a techno-cultural space where creatives meet, deal with technology and negotiate their art and businesses. Although the scope of this research was limited to a single instrument, general observations about the interviewed producers' attitudes and conceptions could be made. The findings suggest that although the producers of this study are principally open towards new technologies, their working practices and musical tastes mostly lead to the use of established (analogue) sounds that are processed either on an analogue console or in a digital audio work station (Pro Tools). Whilst their reasons are manifold, ranging from audio quality to economic strategies, few metal music producers will probably be the driving force for creating utterly new sounds. One reason might be the focus on producers working mainly in the metal genre that has strong links to rock aesthetics, still widely celebrating the classic sounds of the 1960s and 1970s. Surprisingly, the attitudes towards new technologies did not depend on the age of the producers with the youngest being even more conservative than the more experimental older ones. Yet, since only internationally established producers were interviewed, this might be different with another sample. It is possible that aspiring producers are more innovative regarding the creation of new sounds with latest digital technology to stand out and to build their reputation - and because they likely cannot afford expensive analogue gear. For this reason, future research should focus on producers at the beginning of their careers to gain an extended understanding of the present research findings. Additionally, the influences between subgenres of rock, metal and other 'handmade' music could be studied for deeper insights into the attitudes within these scenes. This should be combined with interviews of the bands to find out whether the artists or the producers promote the creation of innovative sounds with modern technologies. Moreover, as the findings might reflect a national phenomenon of German producers, it would be conclusive to extend this study by investigating different national scenes. Finally, the audience should be considered too. Whilst researchers, musicians and producers may have the tendency to look at meticulous sonic and technical details, the audience will listen to the music differently. Such holistic research may still not be able to predict future musical developments and the role of music technology, but it will contribute to an understanding of musical practices including the interrelation of the different elements of production and reception.

\section{References}

Auvinen, T. (2016), 'A new breed of home studio producer: Agency and cultural space in contemporary home studio music production', Etnomusikologian vuosikirja, 28, pp. 1-33.

Bates, E. (2012), 'What Studios Do', Journal on the Art of Record Production, 7, http://arpjournal.com/what-studios-do. Accessed 11 November 2017.

Berger, H. M. (1999), Metal, Rock, and Jazz. Perception and Phenomenology of Musical Experience, Hanover: Wesleyan University Press.

Berger, H. M. and Fales, C. (2005), "Heaviness" in the Perception of Heavy Metal Guitar Timbres. The Match of Perceptual and Acoustic Features over Time', in P. D. Greene and T. Porcello (eds.), Wired for sound. Engineering and technologies in sonic cultures, Middletown, CT: Wesleyan University Press, pp. 181-197. 
Chanan, M. (1995), Repeated takes. A short history of recording and its effects on music, London: Verso.

Cresswell, J. W. (2003), Research Design. Qualitative, Quantitative and Mixed Methods Approaches, Thousand Oaks: Sage.

Davodowich, D. (2015), 'Kemper Profiling Amplifier'. Music Players.com, http://musicplayers.com/reviews/guitars/2015/0115_Kemper.php. Accessed 11 November 2017.

Denscombe, M. (2007), The Good Research Guide for small-scale research projects, Maidenhead: Open University Press.

Eichenberger, D. (2015), 'Giggin without an amp', http://www.seymourduncan.com/blog/tipsand-tricks/gigging-without-an-amp. Accessed 11 November 2017.

Greeves, D. (2012), 'Kemper Profiling Amplifier', Sound on Sound, http://www.soundonsound.com/reviews/kemper-profiling-amplifier. Accessed 11 November 2017.

Herbst, J.-P. (2016), Die Gitarrenverzerrung in der Rockmusik [The guitar distortion in rock music], Münster: Lit.

Herbst, J.-P. (2017), 'Historical development, sound aesthetics and production techniques of the distorted electric guitar in metal music', Metal Music Studies, 3:1, pp. 24-46.

Herbst, J.-P. (2018), 'Heaviness and the electric guitar: Considering the interaction between distortion and harmonic structures', Metal Music Studies, 4:1, pp. 95-113.

Herbst, J.-P., Czedik-Eysenberg, I. \& Reuter, C. (2018), 'Guitar profiling technology in metal music production: public reception, capability, consequences and perspectives', Metal Music Studies, 4:3 (forthcoming).

Jones, S. (1992), Rock Formation. Music, Technology, and Mass Communication, Thousand Oaks: Sage.

Kaiser, C. (2017), 'Analog Distinction - Music Production Processes and Social Inequality', Journal on the Art of Record Production, 11, https://arpjournal.com/analog-distinction-music-production-processes-and-social-inequality. Accessed 20 November 2017.

Kealey, E. R. (1982), 'Conventions and the Production of the Popular Music Aesthetic', Journal of Popular Culture, 16:2, pp. 100-115.

Kemper (2016), Kemper Profiling Guide, https://www.kemper-amps.com/download/87/Profiling-Guide. Accessed 11 November 2017.

Leyshon, A. (2009), 'The Software Slump?: digital music, the democratisation of technology, and the decline of the recording studio sector within the musical economy', Environment and Planning A, 49, pp. 1309-1331.

Martin, A. (2014), The Role and Working Practice of Music Producers: An Interpretative Phenomenological Analysis, $\mathrm{PhD}$ thesis, University of Hull.

Martinelli, R. (2006), 'Interview: Andy Sneap', Maelstrom, 45, http://www.maelstromzine.com/ezine/interview iss45 208.php. Accessed 11 November 2017.

Moore, A. F. (2002), Authenticity as authentication, Popular Music, 21:2, pp. 209-223.

Moorefield, V. (2010), The producer as composer. Shaping the sounds of popular music. London: MIT Press.

Mynett, M. (2013), Contemporary metal music production, Ph.D. thesis, Huddersfield: University of Huddersfield.

Mynett, M. (2017), Metal Music Manual. Producing, Engineering, Mixing, and Mastering Contemporary Heavy Metal, London: Routledge.

Sneap, A. (2012), 'Kemper Profiling Amp - Artist Talk with Andy Sneap', https://www.youtube.com/watch?v=Nb1zI6pEu0A. Accessed 11 November 2017. 
Taylor, M. (2011), 'Interview: Metal production guru Colin Richardson', Musicradar, http://www.musicradar.com/news/guitars/interview-metalproduction-guru-colin-richardson-400260. Accessed 11 November 2017.

Théberge, P. (1993), Consumers of Technology. Musical Instrument Innovations and the Musicians' Market, $\mathrm{PhD}$ thesis, Concordia University.

Théberge, P. (1997), Any sound you can imagine. Making music/consuming technology, Hanover: Wesleyan University Press.

Théberge, P. (2004), 'The Network Studio: Historical and Technological Paths to a New Ideal in Music Making', Social Studies of Science, 34:5, pp. 759-781.

Uimonen, H. (2016), 'Celebrity Guitars: Musical Instruments as Luxury Items', Rock Music Studies, 3:3, pp. 1-19.

Vinnicombe, C. (2012), 'Kemper Profiling Amp', Guitarist, May 2012, pp. 119-122.

Wagener, M. (2013), 'Kemper Producer Talk - Michael Wagener', https://www.youtube.com/watch?v=32kBaZFPzHs. Accessed 11 November 2017.

Walser, R. (1993), Running with the devil. Power, gender, and madness in heavy metal music, Hanover: Wesleyan University Press.

Warner, T. (2003), Pop Music - Technology and Creativity. Trevor Horn and the Digital Revolution, Aldershot: Ashgate.

Williams, D. (2015), 'Tracking timbral changes in metal productions from 1990 to 2013', Metal Music Studies, 1:1, pp. 39-68.

\section{Interviews}

Bauerfeind, K. (2017), Grefrath 25.07.2017. 136 minutes. Interviewer Jan-Peter Herbst. Mp3file in the possession of the author.

Bemm, S. (2017), Hagen 27.07.2017. 67 minutes. Interviewer Jan-Peter Herbst. Mp3-file in the possession of the author.

Kemper, C. (2017), Recklinghausen 2.11.2017. 49 minutes. Interviewer Jan-Peter Herbst. Mp3-file in the possession of the author.

Lammert, L. (2017), Lübeck 19.06.2011. 40 minutes. Interviewer Jan-Peter Herbst. Mp3-file in the possession of the author.

Levermann, S. (2017), Arnsberg 28.06.2017. 32 minutes. Interviewer Jan-Peter Herbst. Written notes in the possession of the author.

\footnotetext{
${ }^{\mathrm{i}}$ For further discussion about the development of guitar technology and guitar players attitudes and uses of equipment see Théberge 1993: 177ff; Herbst 2016: 297ff, Uimonen 2016, and Herbst, Czedik-Eysenberg \& Reuter 2018.

ii In the history of popular music, innovations by use of new studio technologies have often preceded live performances, or work was produced that was impossible to be performed live (Chanan 1995; Warner 2003; Moorefield 2010).

iii The author of this research has no affiliation with Kemper Ltd. The motivation for this study is to explore current and future consequences of profiling technology on professional practices in metal music production.

iv Bemm and Bauerfeind both mention an artificial 'sizzling' sound in the 3-4 kHz area of modern metal amplifiers due to their parallel-circuits, common in transistor designs, to overload the valves more to produce higher levels of distortion.
} 
${ }^{\mathrm{v}}$ In addition to band productions, Lammert offers re-amping and profiling services as part of his business, which guarantees an extra income. Profiling changed the established practice of re-amping because it replaces all future services. As he explains, professional guitar profiles, high-quality drum samplers and the availability of powerful sequencer software have tensed the market situation, especially for advanced but not world-leading producers. Better-established producers such as Bauerfeind and Bemm are less affected by this.

${ }^{v i}$ According to Kemper, combining two or more profiling units in one device is not yet possible due to limited computational power.

vii Metal is a genre that greatly profited from digitalisation because it improved the clarity, allowed extensive layering of tracks to create walls of heavy guitar sounds (Williams 2015), and enabled meticulous editing of fast rhythms, increasing precision and impact (Mynett 2017). Thus, influential early metal music producers as for instance Andy Sneap (Martinelli 2006) and Colin Richardson (Taylor 2011) embraced the potential of such technological innovations. viii Opeth is a good example. Having started as a progressive death metal band, they could now be considered more a progressive rock band with many influences from the 1970s.

ix Without giving away any details, Kemper announced that a new technology will shortly be released, allowing to substitute a real guitar player or to improve mediocre players' skills, however, it would not be Kemper Ltd. providing such a technology.

${ }^{x}$ Reflecting on the social dimension of music production equipment, Kaiser (2017) sees analogue hardware as a symbolic indicator for social position (status) and people's esteem of the owner's status (prestige).

xi The gear list of Lammert's studio begins with guitars, amplifiers and cabinets followed by the microphones, the hardware and software, the plugins, the studio itself and its accommodation.

xii The websites of all producers and their studios further indicate that promoting the studio by its technical capital, the studio equipment, is much more common among the younger producers like Levermann and Lammert. The better-established producers Bauerfeind and Bemm focus more on successful clients. Bauerfeind, fulfilling the traditional role of a producer, does not even have a studio of his own, working either in Blind Guardian's Twilight Hall studio or renting a studio based on his clients' requests. 